Article

\title{
Drivers of Old-Age Dependence and Long-Term Care Usage in Switzerland-A Structural Equation Model Approach
}

\author{
Iegor Rudnytskyi ${ }^{1,+}$ and Joël Wagner ${ }^{1,2, *,+}$ (D) \\ 1 Department of Actuarial Science, Faculty HEC, University of Lausanne, Extranef, \\ 1015 Lausanne, Switzerland \\ 2 Swiss Finance Institute, University of Lausanne, Extranef, 1015 Lausanne, Switzerland \\ * Correspondence: joel.wagner@unil.ch \\ + These authors contributed equally to this work.
}

Received: 16 July 2019; Accepted: 19 August 2019; Published: 26 August 2019

check for updates

\begin{abstract}
Long-term care (LTC) encompasses a set of services provided to impaired and dependent elderly people. To assess the level of the dependence several scales are used, including activities of daily living (ADL), instrumental ADL (IADL) and functional limitations. Once an elderly person fails to perform these activities independently, he or she requires special assistance. Help can be provided as informal care by relatives and as formal care by professionals. The aim of this research is to study individual characteristics that relate to the demand of LTC and to analyze the relation between formal and informal care. We base our study on data from the Swiss Health Survey focusing on respondents aged over 65 years. Using the structural equation modeling technique, we develop a statistical model that considers the dependence concept as a latent variable. This hidden dependence variable combines three indices linked to the limitations in ADL, in IADL and functional limitations. Accounting for causality links between covariates enables us to include the indirect effect of pathologies on the receipt of LTC mediated via dependence. In our model, we do not assume a causal relationship between formal and informal care. From our results, we observe a significant impact of pathologies as well as of the socio-demographic factors on the demand for LTC. The relationship between formal and informal care is found to be of both a complementary and substitutional nature.
\end{abstract}

Keywords: old-age dependence; long-term care (LTC); structural equation model; pathology

\section{Introduction}

The population is aging in many countries in the world and the speed of the process is expected to increase in the future (Lutz et al. 2008). The dramatic growth of the number of elderly triggers a higher demand for long-term care (LTC) services. The latter are defined by the International Labour Office as the "support that is needed by older persons with limited ability to care for themselves due to physical or mental conditions, including chronic diseases and multimorbidity" (Scheil-Adlung 2015, p. 2). Such care can be delivered as informal care by persons from the social network, that is, partners, children, friends or neighbors of a dependent elderly person. Further, formal LTC embodies services and assistance in personal care and domestic tasks by specifically trained and qualified persons. Formal LTC is associated with higher expenditures and raises direct financial challenges on the health policies. As a result, informal care, although coming at a cost to the caregivers, is an important alternative to formal care (Weaver and Weaver 2014). Therefore, investigating the link between formal and informal care is of particular importance (see also, for example, Fuino and Wagner 2019). In policymaking and when defining incentives, it is highly relevant whether the relationship is substitutional or complementary. 
The aim of the present study is to investigate the drivers of old-age dependence and LTC usage in a structural equation modeling (SEM) framework. Relying on data from the Swiss Health Survey (SHS) for the model calibration, our focus is threefold: First, we are interested in the the measurement of dependence, linking dependence with the indices related to the limitations in activities of daily living (ADL), in instrumental ADL (IADL) and to functional limitations. Second, we relate the latent dependence variable to selected covariates including the age, the body mass index (BMI) and selected pathologies. Finally, we derive the factors that relate to formal and informal LTC utilization. Our model includes the gender, the education and income levels, the language region, the number of persons in the household and the presence of children outside of the household. Thereby, modeling formal and informal care usage separately, we study the prevalent correlation between both types of care.

Instead of relying on a single regression model and one dependence measure, the SEM technique allows to measure dependence by several scales ensuring the robustness of the results. Thereby, we mediate the effect of medical conditions on the receipt of LTC via dependence. Using SHS data from the 2017 wave, we find that strokes, heart attacks, bronchitis and diabetes significantly increase the level of dependence. We observe this effect to a lower extent in the case of osteoporosis, arthritis and cancer. Further, higher dependence is associated with higher ages and higher deviations from the average BMI. Being a woman increases the probability to require LTC while neither the education level nor the monthly income significantly changes the probability. Residents from French-speaking cantons report a higher probability of receiving formal care. A higher number of persons living in the same household decreases the consumption of formal care but increases the use of informal care indicating a substitution effect. However, we do not observe any impact of the presence of children outside of the household. Our findings for Switzerland confirm findings from a European study based on the SHARE dataset (cf. Fuino et al. 2019). Finally, we report on the positive correlation between formal and informal care that indicates complementarity.

The remainder of the paper is organized as follows: In Section 2 we discuss the characteristics that can influence the demand for LTC by reviewing the existing literature and presenting the empirical background. We also derive four research hypotheses. Section 3 introduces the available data from the Swiss Health Survey, presents the variables for the empirical model and provides descriptive statistics. In Section 4, we define a statistical model based on SEM, outline our estimation results and review the main findings. We conclude in Section 5.

\section{Development of Research Hypotheses}

In the following, we review the existing literature relating selected risk factors to LTC dependence and care utilization. We derive four research hypotheses.

\subsection{Health Indicators}

Age has been extensively studied in conjunction with LTC dependence. The decline of the general health is associated with the natural process of aging through the frailty syndrome (Fried et al. 2001) which triggers impairment and dependence. Research by House et al. (1990) and Rahmqvist (2001) underlines the relationship between age and self-rated health that is significantly associated with dependence. Further, age is one of the key demographic covariates for assessing the utilization of care facilities (see, for example, Langa et al. 2001a; Michaud and van Soest 2008; Kim and Lim 2015; Coe and Van Houtven 2009; etc.). Another health-related variable is the BMI. While Pi-Sunyer (1991) finds obesity to be a major health risk, Wu et al. (2013) also observe that underweight can affect self-rated health. Using data from European countries, the recent work by Fuino et al. (2019) links underweight and obesity to dependence. Finally, the impact of diseases on the demand for LTC is widely accepted. We start by mentioning, for example, Wong et al. (2010) who study how diagnoses trigger the utilization of different forms of formal care. They find significant influence among diagnoses of cancer, mental diseases (Schizophrenia, dementia and Alzheimer's disease) and others. Similar results are derived in the papers by Shapiro and Tate (1985); Langa et al. (2001a); 
Hanaoka and Norton (2008); Michaud and van Soest (2008); De Meijer et al. (2011); Prince et al. (2013) and GBD DALYs and HALE Collaborators (2017). Most of these studies consider the direct effect of diseases. We will emphasize on the importance to measure the mediated effect through the dependence status and state our first conjecture as follows:

Conjecture 1. The indirect effect of physical diseases, the age and the BMI on the utilization of formal and informal care mediated via dependence is significant and positive.

\subsection{Socio-Demographic Indicators}

In the care literature, the gender of the elderly person is found to play a vital role in predicting and explaining the demand for LTC. Evidence suggests to use the gender as an explanatory variable: women tend to live longer and become disabled at higher ages (Barczyk and Kredler 2018), the type of care provided to women significantly differs from the one provided to men (e.g., Denton 1997) and informal caregivers are mostly female individuals entailing higher receipt of informal care by their male spouses (Kemper 1992 and Wagner and Brandt 2018). Two other essential components are the education and the wealth of the elderly person. Rodrigues et al. (2018) and Freedman and Martin (1999) conclude that the use of LTC significantly differs across the accumulated wealth and Kemper (1992) shows the significant and positive association between monthly income and the probability to receive formal care. Further, the education level is positively associated with the probability of hospitalization in the paper by Weaver and Weaver (2014). Further references that use education and income include papers by Huisman et al. (2003); Hanaoka and Norton (2008); De Meijer et al. (2011); Shapiro and Tate (1985); Tomiak et al. (2000). Fuino and Wagner (2019) find a significant effect of the pre-retirement income on LTC duration.

Cultural aspects are important drivers for the usage of formal and informal LTC. A number of studies report on the so-called North-South gradient in Europe (Bolin et al. 2008; Bonsang 2009; Torbica et al. 2015; and Barczyk and Kredler 2018). For example, Bolin et al. (2008) provide evidence that in Southern European countries informal care plays a very important role, when compared to Central Europe. This is also derived by Fuino et al. (2019). Switzerland has three cultural clusters linked to the spoken languages, namely German-, French- and Italian-speaking parts. The presence of this categorization is well covered, for example, in Fuino and Wagner (2018). Let us stress the paper by Gentili et al. (2017) who observe that French-speaking population is more likely to enter a nursing home with higher dependency level and age, when compared to elderly from the German-speaking part.

Conjecture 2. Socio-demographic variables such as gender, education, income and Swiss language regions have a significant direct effect on the utilization of formal and informal care.

\subsection{Social Environment Factors}

Aspects from the social environment are often used to predict the demand for various types of LTC. In case of informal care, the assistance is mostly provided by spouses (partners) and children, followed by friends and neighbors (Christianson 1988). The number of such caregivers, as well as their specific characteristics (age, gender, proximity, etc.) are associated with the use of informal LTC. For instance, Bakx et al. (2015) indicate the spouse's characteristics as being significant drivers of professional services in the Netherlands. Balia and Brau (2014) account for the distance to the nearest child and find it relevant to the average number of hours of informal care. Selected caregivers' characteristics can help to define the type of care that is demanded (see Conjecture 4 below).

Further, Finlayson (2002) provides a comprehensive and exhaustive list of references for which the relation between the socio-related factors and formal care is investigated. Most of the reviewed studies focus on the number of informal caregivers (typically represented as the number of persons in the household) and various dummy variables, such as living alone, the presence of children, the presence 
of the spouse in the household and the marital status. For example, Newman et al. (1990) emphasize the relationship of living alone and institutional care. As in the case of informal care, factors like the gender and the age of potential caregivers are also considered. Jette et al. (1995) outline a strong increase in the risk of entering the nursing home, in cases of elderly people with a male caregiver, when compared to those with a female available spouse. Fuino et al. (2019) find that the presence of the partner in the household significantly impacts the usage of professional LTC services. The number of persons in the household incorporates the information whether or not the individual has a potential caregiver, regardless whether this is the spouse or a child. Since at higher ages, children mostly live separately from their elderly parents, we account for the presence of children outside of the household.

Conjecture 3. The utilization of formal and informal care strongly depends on the social environment and the household structure. Formal and informal care are negatively, respectively positively, associated with the household size and the presence of children outside household.

\subsection{Relationship between Informal and Formal Care}

The interaction between formal and informal care has been studied extensively during the past decades. The primary question is whether the two types of care are substitutes or complements. Previous empirical studies outline mixed results. Chappell (1985) compares elderly people on their utilization of home-based care using structured interview. The author finds that the relation is complementary and that formal care does not substitute to informal care. Further, Langa et al. (2001b) observe that at-home care services increase the number of hours in case elderly people need greater social support indicating a complementary relationship. Christianson (1988) reports that the increase of formal services has no significant impact on informal care utilization while using an experimental design methodology. Finally, a small substitutional effect has been shown by Pezzin et al. (1996).

Another stream of research emphasizes on the importance of accounting for endogeneity of informally provided care which may otherwise lead to inconsistent findings. To cope with this issue, several studies use an instrumental variable approach pioneered by Van Houtven and Norton (2004) and Lo Sasso and Johnson (2002). Information on family structures, in particular children's characteristics are used as instruments: Charles and Sevak (2005) use the proximity, the gender and the marital status of children, Bolin et al. (2008) employ the age of the oldest child and Bonsang (2009) exploits the proportion of daughters and the distance to the nearest child. In these studies, informal care is found to be to some extent a substitute of formal care. Several recent studies by Weaver and Weaver (2014); Kim and Lim (2015); Torbica et al. (2015) and Mommaerts (2018) confirm these results.

Most studies implicitly assume the causality of one form of care on the other, for example, the effect of receiving informal care on the utilization of formal care. However, the decision on which type of services to use is made simultaneously and the causal link is not fully obvious. Given the complex nature and in order to address a potential bias, we let formal and informal care correlate rather than explain each other. This is possible in a SEM framework.

Conjecture 4. The usage of formal and informal care is positively correlated.

\section{Swiss Health Survey Data and Descriptive Statistics}

\subsection{SHS Dataset}

We base our analysis on the SHS data provided by the Swiss Federal Statistical Office (2019). ${ }^{1}$ The survey is conducted every five years and has started in 1992 yielding six sets of survey data.

1 Detailed information about the survey is available through the website https://www.bfs.admin.ch/bfs/fr/home/ statistiques/sante/enquetes/sgb.html. 
The overall target population of the survey are individuals aged over 15 years permanently living in an individual household in Switzerland. This means in particular that individuals who live in hospitals or medical-social establishments including long-term care institutions are not eligible for an interview ${ }^{2}$ The interview is split into two parts, an interview over-the-phone complemented with a paper- or electronic-based questionnaire. Computer-assisted telephone interviewing, computer-assisted personal interviewing and telephone interviews with a close person are used to ensure the quality of the data. ${ }^{3}$ In the framework of the SHS, the health concept and the quality of life depends on four key aspects: the resources and services in the health sector, the lifestyle and health behavior, the natural and man-made environment and the social environment. Therefore, the interviews cover themes such as sociodemographic characteristics (e.g., gender, age, marital status, education, income, household structure), lifestyle and behavioral risks (e.g., tobacco and alcohol consumption, gambling, physical activity), health (e.g., body measurements, chronic diseases, physical disorders) and health services (e.g., medical consultations, hospitalizations).

In the present research we use the most recent wave of the survey conducted in 2017. It includes raw responses of 22,134 individuals from the phone-based interviews and 18,832 from the written interviews. The survey data are complemented by a file containing indices that summarize groups of raw questions in a convenient, consistent and condensed format. We merge the survey data and indices together along each unique identifier. In our study, we focus only on respondents aged 65 years or older, since LTC utilization occurs at higher ages (Balia and Brau 2014). Restricting the age to be between 65 and 99 years yields a dataset containing 5114 observations. We remove entries with missing values in the variables used in our study and are finally left with 4026 observations.

In the SHS, the level of the dependence is assessed by the number of limitations in ADL, IADL and functional limitations. Five items used for the ADL are similar to the ones used in the original Katz scale (Katz et al. 1963): eating, getting in/out of bed, dressing, toileting and taking a bath or a shower. The SHS scale, however, does not include continence which is used in the Katz scale. Survey participants are asked how they can perform each of these activities within the following answers: "Yes, without difficulty", "Yes, with some difficulty", "Yes, with great difficulty" and "Not at all". In order to convert the categorical answers to numeric ones, we assign to the answers values of 0 , $1 / 3,2 / 3$ and 1 , respectively. Then, we sum up these values over all the activities and divide by five, the number of items of the scale. The resulting $A D L$ variable takes values between 0 and 1 and not only indicates whether or not a respondent is dependent but also relates, to some extent, to the degree of dependency. In a similar manner we construct two variables linked to the limitations in IADL and to the functional limitations. The instrumental activities studied in the SHS include eight items: meal preparation, calling, shopping, doing laundry, doing light housework, occasionally doing heavy housework, doing accounting and using public transport. The answers are again coded as above and the variable $I A D L$ is constructed by averaging over the items. Finally, functional limitations encompass limitations in reading a book or a newspaper, in following a conversation with at least two persons, in walking without assistance and in speaking without difficulty. We construct the FUN variable using these four activities as available from the SHS data.

We now discuss the demographic covariates that we consider in our study. In the survey, the age $A G E$ is represented as an integer number of years in 2017, while the gender variable SEX takes two values, male and female. Further, the SHS contains information on the individuals' monthly income INC in CHF. The value does not include compulsory contributions to social insurance but takes into account supportive payments made or received. The question on education allows for 20 different

2 Given that non-institutionalized individuals are not covered by the survey our sample is not representative of the overall LTC needs at national level and we must be careful when interpreting the results.

3 Elderly persons are often affected by several pathologies (multimorbidity). Despite the process of interviewing in two parts and integrating a close person to ensure the quality of the data, the registered diseases may not be correctly reported, especially in the case of dependent elderly people. This should be kept in mind when considering the results. 
answers for the highest completed level. These answers are summarized in $E D U$, a compact variable along three categories including primary, secondary and tertiary education levels. The language of the interview is a good indicator for the linguistic region LNG of the respondent, namely, German-, Frenchand Italian-speaking areas. Finally, the survey contains information on the height and the weight, making it possible to compute the body mass index (BMI). Typically the distribution of the BMI has a bell shape and absolute deviations from the average BMI are associated with a poorer health status. Therefore, we consider absolute deviations $d B M I$ from the sample mean. To reflect the structure of the household we use the number of persons in the household NPR counting the actual persons living in the same household during more than four days per week. Furthermore, as respondents are asked whether or not they have children outside the household, we include that number in $\mathrm{CHO}$.

The set of pathologies contained in the SHS includes the following diseases: asthma AST, arthritis $A R T$, osteoporosis $O S T$, chronic bronchitis $B R H$, heart attack $A T T$, stroke $S T R$, cancer CNR (any type) and diabetes $D B T .{ }^{4}$ The binary variables representing these diseases have two levels, yes and no, that define whether a respondent has had the illness or problems related to it during the past 12 months. Finally, the utilization of formal FCR and informal ICR care are represented by binary variables indicating whether the respondent has used services over the past 12 months. Formal care encompasses care services provided by professionals at home, including nursing care, help with domestic tasks, personal care, meals-on-wheels and transport services. Informal care covers assistance in physical care, shopping, preparing meals and administrative tasks provided by a spouse or partner, relatives, neighbors or friends.

\subsection{Descriptive Statistics}

In this section, we present descriptive statistics of the respondents' characteristics. Our first conjecture assumes that the effect of diseases, age and BMI on the utilization of LTC is mediated via dependence. Furthermore, the second and the third conjecture focus on the direct effect of individuals' demographic characteristics as well as the social environment on the receipt of LTC. Therefore, we split exogenous variables into two subgroups depending on the factor they are affecting directly, that is, dependence or the utilization of LTC.

\subsection{Exogenous Characteristics Affecting Dependence}

Descriptive statistics of the variables that directly affect dependence are given in Table 1. For each variable and value we provide the number of respondents $N$ and their share within the total data set. For the three scales $A D L, I A D L$ and FUN that measure the dependence, we report the conditional average dependence value considering only non-zero values. Values of the overall sample conditional means (see bottom of the table) are $0.21,0.17$ and 0.14 for $A D L, I A D L$ and FUN, respectively. Among the 4026 respondents, 292 individuals have reported a non-zero value of $A D L$, while the numbers of individuals reporting non-zero values of IADL respectively FUN are 1165 and 970. The two last numbers are higher, since ADL represent activities that are necessary for fundamental functioning and therefore dependence in ADL implies the dependence in less severe IADL and functional limitations. This is in line with, for example, (Spector et al. 1987) who find that the items "shopping" and "transportation" in IADL show lower levels of dependence when compared to ADL. The three dependence indicators are well related to dependence and highly correlate among each others. Table 2 reports information on the correlation and standard deviations of ADL, IADL and FUN.

4 The data does not contain information on mental diseases except for depression. Further, the causal link for depression does not have a clear direction: a respondent can be depressed because of the dependence status, and, conversely, clinical depression can cause dependence. Thus, the absence of questions on mental diseases in the SHS does not allow us to study the role of mental pathologies. 
Table 1. Descriptive statistics of the exogenous characteristics affecting dependence.

\begin{tabular}{|c|c|c|c|c|c|}
\hline Characteristics & $N$ & $(\%)$ & $A D L$ & $I A D L$ & FUN \\
\hline \multicolumn{6}{|l|}{ Age } \\
\hline $65-69$ & 1282 & $(31.8)$ & 0.20 & 0.16 & 0.13 \\
\hline $70-74$ & 1145 & $(28.4)$ & 0.18 & 0.13 & 0.13 \\
\hline $75-79$ & 832 & (20.7) & 0.24 & 0.14 & 0.14 \\
\hline $80-84$ & 483 & $(12.0)$ & 0.15 & 0.16 & 0.14 \\
\hline $85-89$ & 218 & $(5.4)$ & 0.26 & 0.25 & 0.20 \\
\hline $90-94$ & 53 & (1.3) & 0.22 & 0.29 & 0.19 \\
\hline 95-99 & 13 & (0.3) & 0.27 & 0.43 & 0.19 \\
\hline \multicolumn{6}{|l|}{ BMI deviation } \\
\hline $0.00-1.30$ & 1004 & (24.9) & 0.19 & 0.15 & 0.15 \\
\hline $1.31-2.62$ & 1009 & $(25.1)$ & 0.25 & 0.16 & 0.13 \\
\hline $2.63-4.64$ & 1005 & $(25.0)$ & 0.17 & 0.14 & 0.13 \\
\hline $4.65+$ & 1008 & $(25.0)$ & 0.22 & 0.20 & 0.16 \\
\hline \multicolumn{6}{|l|}{ Asthma } \\
\hline No & 3841 & $(95.4)$ & 0.20 & 0.17 & 0.14 \\
\hline Yes & 185 & $(4.6)$ & 0.23 & 0.16 & 0.15 \\
\hline \multicolumn{6}{|l|}{ Arthritis } \\
\hline No & 2615 & $(65.0)$ & 0.23 & 0.17 & 0.13 \\
\hline Yes & 1411 & $(35.0)$ & 0.19 & 0.16 & 0.15 \\
\hline \multicolumn{6}{|l|}{ Osteoporosis } \\
\hline No & 3639 & $(90.4)$ & 0.21 & 0.16 & 0.14 \\
\hline Yes & 387 & $(9.6)$ & 0.20 & 0.19 & 0.16 \\
\hline \multicolumn{6}{|l|}{ Bronchitis } \\
\hline No & 3833 & (95.2) & 0.20 & 0.16 & 0.14 \\
\hline Yes & 193 & $(4.8)$ & 0.24 & 0.23 & 0.17 \\
\hline \multicolumn{6}{|l|}{ Heart attack } \\
\hline No & 3984 & (99.0) & 0.20 & 0.17 & 0.14 \\
\hline Yes & 42 & $(1.0)$ & 0.43 & 0.22 & 0.19 \\
\hline \multicolumn{6}{|l|}{ Stroke } \\
\hline No & 3983 & (98.9) & 0.21 & 0.16 & 0.14 \\
\hline Yes & 43 & $(1.1)$ & 0.22 & 0.35 & 0.22 \\
\hline \multicolumn{6}{|l|}{ Cancer } \\
\hline No & 3851 & (95.7) & 0.21 & 0.17 & 0.14 \\
\hline Yes & 175 & $(4.3)$ & 0.15 & 0.16 & 0.12 \\
\hline \multicolumn{6}{|l|}{ Diabetes } \\
\hline No & 3652 & (90.7) & 0.20 & 0.16 & 0.14 \\
\hline Yes & 374 & $(9.3)$ & 0.23 & 0.23 & 0.18 \\
\hline Total & & & 0.21 & 0.17 & 0.14 \\
\hline$N$ & 4026 & (100.0) & 292 & 1165 & 970 \\
\hline
\end{tabular}

Table 2. Correlation coefficients and standard deviation of the dependence indicator variables.

\begin{tabular}{cccc}
\hline Variables & ADL & IADL & FUN \\
\hline ADL & 1.00 & 0.67 & 0.49 \\
IADL & 0.67 & 1.00 & 0.63 \\
FUN & 0.49 & 0.63 & 1.00 \\
\hline Std. dev. & 0.08 & 0.14 & 0.08 \\
\hline
\end{tabular}


From Table 1 we see that the dataset mainly consists of respondents aged below 85 (93\%). We observe that the $A D L$ variable does not show a perfectly increasing trend through age groups, which can be explained by the fact that, with a higher number of limitations, elderly people enter nursing homes and are no more represented in the SHS. Further, we note that the average IADL and FUN values consistently increase with the age. We group respondents according to their absolute deviations from the sample BMI mean. To form four classes we use sample quartiles that are bounded at deviations of $1.31(25 \%), 2.63(50 \%)$ and $4.65(75 \%)$. We find that dependency levels increase with BMI deviation. For the group with the largest BMI deviation (4.65+), the averages of all scales are larger when compared to the groups with lower deviations.

Finally, we cover statistics along selected diseases. Arthritis comes with the highest number of reported dependence cases, which equals to 1411 respondents and corresponds to $35.0 \%$ of the sample. In contrast, the lowest proportion of diseased (1.0\%) have had a heart attack (42 cases). Nevertheless heart attacks relate to the highest average $A D L(0.43)$. Such differences can be explained by severe rehabilitation measures after myocardial infarction (Witt et al. 2004). Heart attack is followed by bronchitis, asthma, diabetes and stroke. These pathologies also relate to an important increase in limitations among respondents who have reported such diseases when compared to those who have not. Cancer, ${ }^{5}$ arthritis and osteoporosis have a lower $A D L$ index. The only diseases that lead to a decreasing $I A D L$ are asthma, arthritis and cancer. The highest increase in limitations comes from stroke. The latter often leads to a strong cognitive decline or even dementia associated with limitations in instrumental activities, especially in those that require cognitive abilities (Brainin et al. 2015). Similar results are obtained for FUN. Both cardio-vascular diseases, heart attack and stroke, yield the highest values of FUN. Overall, we conclude that most diseases substantially increase the dependence indicators.

\subsection{Exogenous Characteristics Affecting LTC Usage}

The second set of exogenous covariates directly relates to LTC usage. In addition to gender, education, income, language group and the household composition, we consider three variables that describe the state of dependence, that is, $A D L, I A D L$ and FUN. For each of these exogenous variables we provide the shares of respondents who have reported formal and informal care utilization. These figures are shown in Table 3. Among the 4026 observations, $6.6 \%$ of the respondents have used formal care, while more than double of this share $(13.7 \%)$ have required informal assistance.

Table 3. Descriptive statistics of the exogenous characteristics affecting long-term care (LTC) usage.

\begin{tabular}{lcccccc}
\hline \multirow{2}{*}{ Characteristics } & \multirow{N}{*}{$\mathbf{N}$} & $\mathbf{( \% )}$ & \multicolumn{2}{c}{ Formal Care } & \multicolumn{2}{c}{ Informal Care } \\
\cline { 4 - 7 } & & & without (\%) & with (\%) & without (\%) & with (\%) \\
\hline Gender & & & & & & \\
$\quad$ Male & 1943 & $(48.3)$ & 95.6 & 4.4 & 90.0 & 10.0 \\
$\quad$ Female & 2083 & $(51.7)$ & 91.5 & 8.5 & 82.8 & 17.2 \\
\hline Education & & & & & & \\
$\quad \begin{array}{l}\text { Primary } \\
\text { Secondary }\end{array}$ & 905 & $(22.5)$ & 91.0 & 9.0 & 83.1 & 16.9 \\
$\quad$ Tertiary & 995 & $(52.8)$ & 93.7 & 6.3 & 86.8 & 13.2 \\
\hline
\end{tabular}

5 The SHS data does not contain any specific information on the type of cancer except for prostate and breast cancer for male respectively female respondents. Although, for the latter, the data does not indicate which person has a positive test, we know that the number of male (female) respondents having examined for prostate (breast) cancer is 1439 (1644 for a pap test and 1649 for mammography), among which 450 (243) individuals have made this test because of pain or similar symptoms. 
Table 3. Cont.

\begin{tabular}{|c|c|c|c|c|c|c|}
\hline \multirow{2}{*}{ Characteristics } & \multirow{2}{*}{$N$} & \multirow{2}{*}{$(\%)$} & \multicolumn{2}{|c|}{ Formal Care } & \multicolumn{2}{|c|}{ Informal Care } \\
\hline & & & without (\%) & with (\%) & without (\%) & with (\%) \\
\hline \multicolumn{7}{|c|}{ Income (in CHF) } \\
\hline 0-1749 & 995 & $(24.7)$ & 94.0 & 6.0 & 83.5 & 16.5 \\
\hline 1750-2999 & 1013 & (25.2) & 91.8 & 8.2 & 85.1 & 14.9 \\
\hline $3000-4999$ & 1008 & $(25.0)$ & 94.2 & 5.8 & 87.5 & 12.5 \\
\hline $5000+$ & 1010 & (25.1) & 93.8 & 6.2 & 88.9 & 11.1 \\
\hline \multicolumn{7}{|c|}{ Language region } \\
\hline German & 2778 & $(69.0)$ & 94.3 & 5.7 & 86.5 & 13.5 \\
\hline French & 925 & $(23.0)$ & 91.1 & 8.9 & 87.2 & 12.8 \\
\hline Italian & 323 & $(8.0)$ & 92.3 & 7.7 & 81.1 & 18.9 \\
\hline \multicolumn{7}{|c|}{ Number of persons in household } \\
\hline 1 & 1189 & $(29.5)$ & 87.5 & 12.5 & 84.4 & 15.6 \\
\hline 2 & 2561 & $(63.6)$ & 95.9 & 4.1 & 87.4 & 12.6 \\
\hline $3+$ & 276 & $(6.9)$ & 96.0 & 4.0 & 83.3 & 16.7 \\
\hline \multicolumn{7}{|c|}{ Children (outside the household) } \\
\hline Yes & 3316 & $(82.4)$ & 93.8 & 6.2 & 86.2 & 13.8 \\
\hline No & 710 & $(17.6)$ & 91.8 & 8.2 & 86.8 & 13.2 \\
\hline \multicolumn{7}{|c|}{ ADL scale $(A D L)$} \\
\hline 0 & 3734 & $(92.7)$ & 95.8 & 4.2 & 89.7 & 10.3 \\
\hline $0.000-0.249$ & 215 & $(5.3)$ & 69.3 & 30.7 & 49.8 & 50.2 \\
\hline $0.250-0.499$ & 49 & $(1.2)$ & 49.0 & 51.0 & 18.4 & 81.6 \\
\hline $0.500-0.749$ & 14 & $(0.3)$ & 35.7 & 64.3 & 0.0 & 100.0 \\
\hline $0.750-1.000$ & 14 & $(0.3)$ & 57.1 & 42.9 & 50.0 & 50.0 \\
\hline \multicolumn{7}{|c|}{ IADL scale $(I A D L)$} \\
\hline 0 & 2861 & $(71.1)$ & 97.9 & 2.1 & 94.8 & 5.2 \\
\hline $0.001-0.249$ & 935 & $(23.2)$ & 88.6 & 11.4 & 75.6 & 24.4 \\
\hline $0.250-0.499$ & 121 & $(3.0)$ & 65.3 & 34.7 & 34.7 & 65.3 \\
\hline $0.500-0.749$ & 51 & (1.3) & 43.1 & 56.9 & 17.6 & 82.4 \\
\hline $0.750-1.000$ & 58 & $(1.4)$ & 56.9 & 43.1 & 6.9 & 93.1 \\
\hline \multicolumn{7}{|c|}{ Functional limitations scale (FUN) } \\
\hline 0 & 3056 & (75.9) & 96.1 & 3.9 & 90.5 & 9.5 \\
\hline $0.001-0.249$ & 803 & (19.9) & 89.3 & 10.7 & 80.3 & 19.7 \\
\hline $0.250-0.499$ & 147 & $(3.7)$ & 64.6 & 35.4 & 40.8 & 59.2 \\
\hline $0.500-0.749$ & 15 & $(0.4)$ & 60.0 & 40.0 & 0.0 & 100.0 \\
\hline $0.750-1.000$ & 5 & $(0.1)$ & 60.0 & 40.0 & 20.0 & 80.0 \\
\hline Total & 4026 & 100.0 & 93.4 & 6.6 & 86.3 & 13.7 \\
\hline
\end{tabular}

Our dataset is composed of $48.3 \%$ men and $51.7 \%$ women. Female respondents show almost twice as high percentage values of use of formal (8.5\%) and informal care $(17.2 \%)$ when compared to the male respondents ( $4.4 \%$ and $10.0 \%$, respectively). About half of the sample has completed secondary education, while the rest of respondents are rather equally split among primary and tertiary education levels. We note that for both formal and informal care, the primary education has the highest share of reported use of LTC, followed by secondary and tertiary. In our sample, the reported monthly income spans from zero to CHF 150,000. To categorize this variable, we use sample quartiles that are bounded at the thresholds of CHF 1750, 3000 and 5000, respectively. We remark that the use of informal care decreases with the income. However, this pattern does not hold for formal care. The majority of individuals have responded to the questions in German (2778), followed by French (925) and Italian (323). The Italian-speaking respondents indicate a higher use of informal care (18.9\% versus $12.8 \%$ and $13.5 \%)$.

The number of persons in the household ranges from one to nine and most respondents live in two persons households (63.6\%). We observe most important differences in the distributions when considering the number of persons in the household for formal care. In the case where people live 
alone, $12.5 \%$ of the respondents use professional assistance. This number decreases to $4.1 \%$ and $4.0 \%$ in cases where two or three and more persons live together. A similar drop is observed for informal care in two persons households. Further, we conclude that most of the respondents have children outside the household (82.4\%). This is a relevant indicator for professional assistance, when children can help to avoid formal care usage.

We note that the utilization of both care types importantly increases along the three $A D L, I A D L$ and FUN scales. Throughout the statistics, this effect is expected and consistent. The smaller number of observations (less than 15) in classes with higher limitations may explain slight deviations. We observe that the increase is less rapid in IADL when compared to the effect of $A D L$. The functional limitations impact the consumption of formal and informal care less than the other two measures.

Finally, we find that both types of care are used side-by-side in a complementary way by elderly people. Table 4 reports the confusion matrix of informal and formal care.

Table 4. Confusion matrix of informal and formal LTC usage.

\begin{tabular}{lccc}
\hline & \multicolumn{3}{c}{ Formal Care } \\
\hline Informal Care & No & Yes & Total \\
\hline No & 3354 & 119 & 3473 \\
Yes & 408 & 145 & 553 \\
\hline Total & 3762 & 264 & 4026 \\
\hline
\end{tabular}

\section{Model Setup, Results and Discussion}

\subsection{Structural Equation Model}

In our study, we develop a model on the framework of SEM. This choice is driven by several methodological requirements. First, the concept of dependence cannot be measured directly by a unique single measure. However, it is well represented as a latent (hidden) variable using a factor analysis approach linked to dependency indicators. Further, our first conjecture assumes the effect of physical characteristics on the receipt of LTC. The link, however, between the usage of LTC and physical characteristics is not direct but conducted through the status of dependence. In addition, these links are assumed to have directions of causality that can be modeled in a framework of path analysis. The combination of factor and path analysis embodies the principles of SEM (see, e.g., Beran and Violato 2010 and Nachtigall et al. 2003). Despite the high level of utilization of SEM in the clinical, behavioral psychology, health sciences and epidemiology literature, it is less used in economics contexts. Nevertheless, several studies by Baranoff et al. (2007); Lu et al. (2012); Eling and Marek (2013) and references therein have applied SEM in the insurance context. Finally, we note that actuarial approaches like survival models cannot be applied since the SHS data are not longitudinal.

Figure 1 presents the SEM that we develop in the sequel. In the following we discuss the three major parts of the model, namely, the measurement of dependence, the regression of physical characteristics for dependence and, finally, the regression for which the usage of formal and informal care are endogenous variables. For developing the two regression models for dependence and for LTC usage, we consider the characteristics that directly relate to dependence respectively to LTC usage. Thereby, as illustrated in Figure 1, we only use each available covariate once. ${ }^{6}$ We lay out the partial models below and Table 5 summarizes the variables used.

6 While developing the models presented below, we have tested alternative specifications, including, for example, the effect of the gender on dependence and the direct effect of the age on LTC usage. None of the tested combinations yields a better goodness-of-fit nor significance of the characteristics. Further, we do not consider interaction terms in order to keep the model simple. 
Table 5. Description of the variables used in the model.

\begin{tabular}{cccc}
\hline Variables & Type & Description & Values \\
\hline$A G E$ & Exogenous & Age & from 65 to 99 \\
$d B M I$ & Exogenous & Deviations from BMI & from 0 to 42.4 \\
$A S T$ & Exogenous & Asthma & yes, no \\
$A R T$ & Exogenous & Arthritis & yes, no \\
$O S T$ & Exogenous & Osteoporosis & yes, no \\
$B R H$ & Exogenous & Bronchitis & yes, no \\
$A T T$ & Exogenous & Heart attack & yes, no \\
$S T R$ & Exogenous & Stroke & yes, no \\
$C N R$ & Exogenous & Cancer & yes, no \\
$D B T$ & Exogenous & Diabetes & yes, no \\
$D E P$ & Latent & Dependence level & - \\
$A D L$ & Manifest & Level of ADL limitations & from 0 to 1 \\
$I A D L$ & Manifest & Level of IADL limitations & from 0 to 1 \\
$F U N$ & Manifest & Level of functional limitations & from 0 to 1 \\
$S E X$ & Exogenous & Gender & male, female \\
$E D U$ & Exogenous & Education level & primary, secondary, tertiary \\
$S I N C$ & Exogenous & Standardized monthly income & from 0.8 to 33.1 \\
$L N G$ & Exogenous & Language region & German, French, Italian \\
$N P R$ & Exogenous & Number of persons in the household & from 0 to 9 \\
$C H O$ & Exogenous & Children outside of the household & yes, no \\
$F C R$ & Endogenous & Use of formal care & yes, no \\
$I C R$ & Endogenous & Use of informal care & yes, no \\
\hline
\end{tabular}

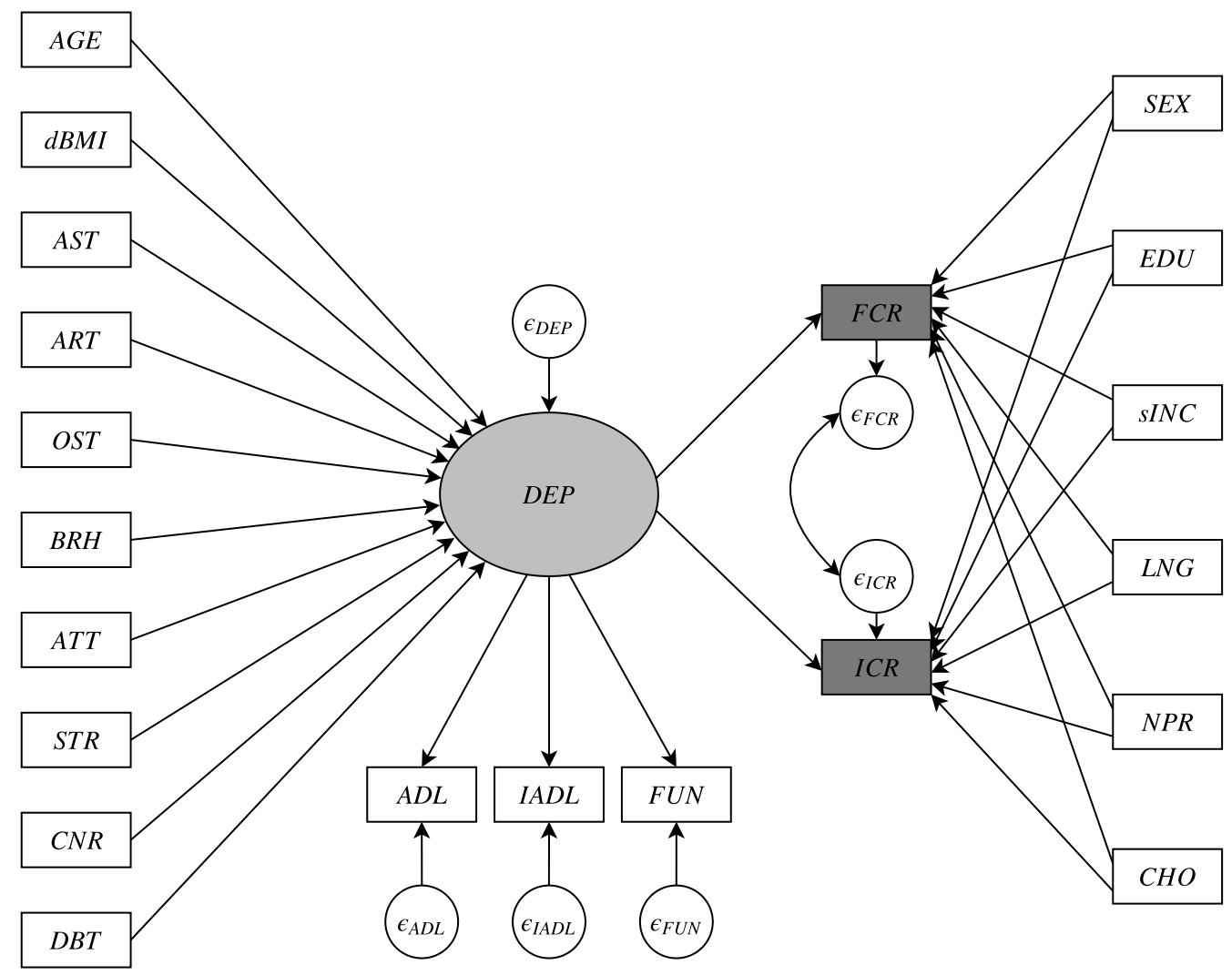

Figure 1. Graphical representation of the proposed structural equation model (SEM).

\subsection{Measurement of Dependence}

We now describe how the concept of dependence is modeled as a latent unobservable variable. The latent variable is measured by indicators, so-called manifest variables, which are assumed to 
perfectly correlate with the underlying concept. We select three indicators to assess the dependence: the measure of limitations in ADL $(A D L)$, of limitations in IADL (IADL) and of functional limitations $(F U N)$. The system of equations that represents the measurement of dependence model, can be formulated as follows:

$$
\begin{aligned}
A D L_{i} & =\lambda_{A D L} D E P_{i}+\epsilon_{A D L, i}, \\
I A D L_{i} & =\lambda_{I A D L} D E P_{i}+\epsilon_{I A D L, i}, \\
F U N_{i} & =\lambda_{F U N} D E P_{i}+\epsilon_{F U N, i} .
\end{aligned}
$$

In the system of Equation (1), $\lambda_{A D L}, \lambda_{I A D L}$ and $\lambda_{F U N}$ are factor loadings corresponding to the magnitude of expected change in the observed variable for a one unit change in the latent variable. The terms $\epsilon_{A D L, i}, \epsilon_{I A D L, i}$ and $\epsilon_{F U N, i}$ are error terms for the individual $i$. The error terms are assumed to be uncorrelated with each other, with the latent variable $D E P$ and to have an expected value of zero.

\subsection{Regression Model for Dependence}

Further, we formulate the simultaneous equations, which determine the interdependence of the variables in our model. First, we determine the relationship between the age, the BMI and the pathologies with the latent variable of dependence:

$$
\begin{aligned}
D E P_{i}= & \beta_{0}+\beta_{A G E} A G E_{i}+\beta_{d B M I} d B M I_{i}+\beta_{A S T} A S T_{i}+\beta_{A R T} A R T_{i}+\beta_{O S T} O S T_{i} \\
& +\beta_{B R H} B R H_{i}+\beta_{A T T} A T T_{i}+\beta_{S T R} S T R_{i}+\beta_{C N R} C N R_{i}+\beta_{D B T} D B T_{i}+\epsilon_{D E P, i} .
\end{aligned}
$$

Here $A G E_{i}$ is the respondent's age, $d B M I_{i}$ is the absolute value of deviation from the average BMI and $A S T_{i}, A R T_{i}, O S T_{i}, B R H_{i}, A T T_{i}, S T R_{i}, C N R_{i}, D B T_{i}$ are binary variables taking the value of one if the respondent has been diagnosed with asthma, arthritis, osteoporosis, bronchitis, heart attack, stroke, cancer and diabetes, respectively and zero otherwise. We denote the regression coefficients by $\beta$ with respective subscripts according to the independent variables. The intercept is denoted by $\beta_{0}$. The error term expressed through $\epsilon_{D E P, i}$ is assumed to have a zero expected value, a constant variance for all $i$ and not to be correlated with the other error terms.

\subsection{Regression Model for LTC Usage}

Two equations express the dependence of formal and informal care receipt on socio-demographic characteristics and dependence. The variables FCR and ICR are taking a value of one, if the respondent has reported receiving formal respectively informal LTC and zero otherwise. We use an unobserved-variable formulation in a probit regression model, which assumes that there exist underlying continuous unobserved variables $F C R^{*}$ and $I C R^{*}$ that are related to $F C R$ respectively ICR as follows:

$$
F C R_{i}= \begin{cases}1 & \text { if } F C R_{i}^{*}>0 \\ 0 & \text { otherwise }\end{cases}
$$

and

$$
I C R_{i}= \begin{cases}1 & \text { if } I C R_{i}^{*}>0, \\ 0 & \text { otherwise. }\end{cases}
$$

Therein, the unobserved variables are defined by:

$$
\begin{aligned}
F C R_{i}^{*}= & \gamma_{0}^{F C R}+\gamma_{D E P}^{F C R} \cdot D E P_{i}+\gamma_{S E X}^{F C R} \cdot S E X_{i}+\gamma_{E D U}^{F C R} \cdot E D U_{i}+\gamma_{S I N C}^{F C R} \cdot s I N C_{i} \\
& +\gamma_{L N G}^{F C R} \cdot L N G_{i}+\gamma_{N P R}^{F C R} \cdot N P R_{i}+\gamma_{C H O}^{F C R} \cdot C H O_{i}+\epsilon_{F C R, i}
\end{aligned}
$$

and 


$$
\begin{aligned}
I C R_{i}^{*}= & \gamma_{0}^{I C R}+\gamma_{D E P}^{I C R} \cdot D E P_{i}+\gamma_{S E X}^{I C R} \cdot S E X_{i}+\gamma_{E D U}^{I C R} \cdot E D U_{i}+\gamma_{S I N C}^{I C R} \cdot s I N C_{i} \\
& +\gamma_{L N G}^{I C R} \cdot L N G_{i}+\gamma_{N P R}^{I C R} \cdot N P R_{i}+\gamma_{C H O}^{F C R} \cdot C H O_{i}+\epsilon_{I C R, i} \cdot
\end{aligned}
$$

In Equations (5) and (6), SEX $, E D U_{i}, \operatorname{SINC}_{i}, L N G_{i}, N P R_{i}$ and $C H O_{i}$ are the gender, education level, standardized monthly income, ${ }^{7}$ language region, number of persons in household and presence of children outside household, respectively. The $\gamma$ denote the regression coefficients with $\gamma_{0}^{F C R}$ and $\gamma_{0}^{I C R}$ being the model intercepts. Subscripts of the $\gamma$ coefficients refer to the corresponding independent variable while superscripts relate to the type of care model (formal care in Equation (5) and informal care in Equation (6)). We take the assumption that both terms $\epsilon_{F C R, i}$ and $\epsilon_{I C R, i}$ are standard normally distributed and allow them to correlate with each other.

\subsection{Results and Discussion}

We show our SEM results in Tables 6-8. In each submodel we report the factor loadings for the measurement of the latent dependence variable, the regression coefficient estimates, the standard errors and their statistical significance. By convention, all coefficients are standardized, that is, each coefficient is multiplied by the ratio of the standard deviations of the explanatory and the dependent variable. This enables the following interpretation: the standardized regression coefficients represent the expected change of the dependent variable in standard deviation units per standard deviation unit change in the explanatory variable while holding all other explanatory variables constant. We do not report the intercept, since by convention deviations from the mean are considered. We indicate statistical significance by "." when the $p$-value is below 0.1 , by "**" when it is below 0.05 , by “*** when it is below 0.01 and by "****" when it is below 0.001 .

Table 6. Results for the measurement of dependence (model 1).

\begin{tabular}{cccc}
\hline \multirow{2}{*}{ Model } & \multicolumn{3}{c}{ Dependence Measurement (1) } \\
\cline { 2 - 4 } & \multicolumn{1}{c}{$\lambda$} & Std. dev. & Sig. \\
\hline$A D L_{i} \sim \lambda_{A D L} D E P_{i}$ & 1.000 & & \\
$I A D L_{i} \sim \lambda_{I A D L} D E P_{i}$ & 2.312 & $(0.027)$ & $* * *$ \\
$F U N_{i} \sim \lambda_{F U N} D E P_{i}$ & 0.964 & $(0.012)$ & $*$ \\
\hline \multicolumn{4}{c}{$p<0.1,{ }^{*} p<0.05,{ }^{* *} p<0.01,{ }^{* * *} p<0.001}$.
\end{tabular}

Table 7. Results for the regression model for dependence (model 2).

\begin{tabular}{lccc}
\hline \multirow{2}{*}{ Variables } & \multicolumn{4}{c}{ Dependence (2) } \\
\cline { 2 - 4 } & $\beta$ & Std. dev. & Sig. \\
\hline Age & 0.002 & $(0.0001)$ & $* * *$ \\
BMI deviations & 0.001 & $(0.0003)$ & $* * * *$ \\
$\begin{array}{l}\text { Asthma (baseline: No) } \\
\text { Yes }\end{array}$ & 0.000 & $(0.0046)$ & \\
\hline
\end{tabular}

7 The values of INC range from zero to CHF 150,000 yielding a high scale of variance, when compared to the other variables. In order to attain better robustness while calibrating the model, we standardize the income and consider $s I N C=(I N C-\overline{I N C}) / s_{I N C}$, where $\overline{I N C}$ and $s_{I N C}$ are the sample mean and the sample standard deviation $I N C$, respectively. 
Table 7. Cont

\begin{tabular}{|c|c|c|c|}
\hline \multirow{2}{*}{ Variables } & \multicolumn{3}{|c|}{ Dependence (2) } \\
\hline & $\beta$ & Std. dev. & Sig. \\
\hline \multicolumn{4}{|c|}{ Arthritis (baseline: No) } \\
\hline Yes & 0.008 & $(0.0021)$ & $* * *$ \\
\hline \multicolumn{4}{|c|}{ Osteoporosis (baseline: No) } \\
\hline Yes & 0.012 & $(0.0028)$ & $* * *$ \\
\hline \multicolumn{4}{|c|}{ Bronchitis (baseline: No) } \\
\hline Yes & 0.035 & $(0.0034)$ & $* * *$ \\
\hline \multicolumn{4}{|c|}{ Heart attack (baseline: No) } \\
\hline Yes & 0.034 & $(0.0055)$ & $* * *$ \\
\hline \multicolumn{4}{|c|}{ Stroke (baseline: No) } \\
\hline Yes & 0.071 & $(0.0047)$ & $* * *$ \\
\hline \multicolumn{4}{|c|}{ Cancer (baseline: No) } \\
\hline Yes & 0.007 & $(0.0049)$ & \\
\hline \multicolumn{4}{|c|}{ Diabetes (baseline: No) } \\
\hline Yes & 0.020 & $(0.0026)$ & $* * *$ \\
\hline
\end{tabular}

Table 8. Results for the regression models for LTC usage (models 5 and 6).

\begin{tabular}{|c|c|c|c|c|c|c|}
\hline \multirow{2}{*}{ Variables } & \multicolumn{3}{|c|}{ Formal Care (5) } & \multicolumn{3}{|c|}{ Informal Care (6) } \\
\hline & $\gamma$ & Std. dev. & Sig. & $\gamma$ & Std. dev. & Sig \\
\hline \multicolumn{7}{|l|}{ Dependence } \\
\hline & 6.498 & $(0.277)$ & $* * *$ & 8.304 & $(0.238)$ & $* * *$ \\
\hline \multicolumn{7}{|c|}{ Gender (baseline: Male) } \\
\hline Female & 0.232 & $(0.079)$ & $* *$ & 0.350 & $(0.059)$ & $* * *$ \\
\hline \multicolumn{7}{|c|}{ Education (baseline: Primary) } \\
\hline Secondary & -0.028 & $(0.081)$ & & 0.000 & $(0.066)$ & \\
\hline Tertiary & 0.019 & $(0.106)$ & & 0.058 & $(0.083)$ & \\
\hline \multicolumn{7}{|l|}{ Income } \\
\hline & -0.014 & $(0.043)$ & & 0.030 & $(0.023)$ & \\
\hline \multicolumn{7}{|c|}{ Language region (baseline: German) } \\
\hline French & 0.223 & $(0.079)$ & ** & -0.110 & $(0.065)$ & \\
\hline Italian & 0.051 & $(0.127)$ & & 0.133 & $(0.091)$ & \\
\hline \multicolumn{7}{|c|}{ Number of persons in household } \\
\hline & -0.298 & $(0.056)$ & $* * *$ & 0.108 & $(0.038)$ & ** \\
\hline \multicolumn{7}{|c|}{ Children (outside household) (baseline: No) } \\
\hline Yes & -0.072 & $(0.084)$ & & 0.044 & $(0.069)$ & \\
\hline
\end{tabular}

Our model is fitted using a three-stage diagonally weighted least squares estimation, which does not require the multivariate normal distribution assumption of the endogenous variables in contrast to the maximum likelihood method (Muthén 1993). We calibrate the model by utilizing the R package lavaan (Rosseel 2012). Our model has 68 degrees of freedom and we find the following goodness-of-fit measures: Tucker Lewis Index of 0.998, Comparative Fit Index of 0.984, Root Mean Square Error of Approximation of 0.034 and Standardized Root Mean Square Residual of 0.024. According to the cut-off points (Hooper et al. 2008), these measures indicate a good fit. We intentionally do not present the chi-square $p$-value because it does not tolerate violation of multivariate normality and would reject the model even if it were correctly specified. Further, our sample is considered as rather large which may also lead to false rejections (see, e.g., Hooper et al. 2008 and the references therein for details on SEM goodness-of-fit). 


\subsection{Measurement of Dependence}

We choose to set the scale of the latent variable $D E P$ to its first indicator $A D L$ in Equation (1). When the level of limitations in ADL is high, this scale assumes higher values of DEP associated with a higher level of dependence. We report factor loadings $\lambda$ as well as their standard deviation and statistical significance in Table 6. The factor loadings of the other two indicators, the level of limitations with IADL and of functional limitations, have positive and significant values of 2.312 and 0.964, implying that three variables reliably measure the latent construct.

\subsection{Regression Model for Dependence}

We now highlight the regression model (2) for which the dependence DEP is the outcome variable. The $\beta$ coefficient estimates, standard deviations and their significance are reported in Table 7. Expectedly, the impact of the age on the dependence is significant and positive, meaning that individuals are expected to have higher levels of dependence at higher ages. Indeed, as mentioned before, higher ages trigger the frailty syndrome associated with poorer health implying strong impairment. The deviation from normal BMI is also found to affect the state of dependence significantly. The positive value of the coefficient indicates that for one standard deviation increase of BMI deviation, the value of the hidden variable of dependence will increase by 0.001 standard deviations. Deviations from the normal BMI are typically considered as indication of severe diseases. For instance, a low BMI is a risk factor for fractures (De Laet et al. 2005) while an increased BMI is associated with an increased risk for various types of cancer (Renehan et al. 2008), cardio-vascular diseases (Gregg et al. 2005) and stroke (Kurth et al. 2002 and Rexrode et al. 1997).

All considered diseases, except asthma and cancer, have a statistically significant impact on dependence. Headen (1993) finds that asthma decreases the hazard of entering the nursing home by $25 \%$ when compared to those who do not have a respiratory disease. At the same time, respiratory diseases increase the hazard of death by the same share. This result allows us to assume that chronic asthma skips the state of dependence leading directly to death of an individual. We note that stroke, bronchitis and heart attack show the highest coefficients. (Tomiak et al. 2000) find that, after mental diseases, stroke is a major factor of entering a nursing home. The aftermath of cardio-vascular diseases is typically associated with a long rehabilitation process among survivors (Torbica et al. 2015) and, therefore, yields higher utilization of care services. We could not find similar results in the case of bronchitis which is typically combined with other chronic obstructive pulmonary diseases (COPD). Since many researchers also consider asthma as COPD and combine it together with bronchitis, it is hard to distinguish the separate effect of these pathologies.

Individuals diagnosed with diabetes have a higher risk of becoming dependent. According to Charles and Sevak (2005) who also find diabetes to increase the probability of entering the nursing home, diabetes is associated with a severe condition of heart illness. Further, even though arthritis and osteoporosis are two different diseases with different diagnoses and symptoms, in the context of dependence, they show similar results. Finally, we report that cancer does not affect the dependence status significantly. The explanation is similar to asthma: cancer often leads to earlier death than other diseases and comes with lower needs for care.

\subsection{Regression Models for LTC Usage}

When analyzing the drivers of demand for formal and informal LTC through the $\gamma$ coefficients statistics reported in Table 8, we observe a significant association with dependence. Further, the link between dependence and care is even stronger for informal care. In line with the consistent observations from previous studies, we find a significant effect of the gender variable: female respondents tend to have a higher probability to receive LTC. This can be explained by the lower mortality and higher frailty at high ages among women. Neither education nor income plays a significant role in explaining the usage of LTC. At first glance, this result might look confusing because both education and income 
are indicators of socio-economic status and also proxies of the profession. However, the risk related to the earlier profession of the respondent is also likely to be incorporated in the observed chronic diseases that enter the model via dependence. Another possible explanation is that in Switzerland about $65 \%$ of costs related to health care are provided by compulsory health insurance and only $20 \%$ are paid out-of-pocket (Gentili et al. 2017). This holds true in particular for at-home based care (recipients of institutional care are rather absent from the survey data). Therefore, there may be little incentive to save money by substituting formal care by informal care.

The respondents who have completed the survey in French show significantly higher receipt of formal care and lower usage of informal care. This result coincides with the conclusion made by Gentili et al. (2017) who highlight differences in German- and French-speaking parts of Switzerland. Their main finding is that the French-speaking population enters nursing homes only with higher dependence status. As our sample does not contain elderly people residing in nursing homes, respondents of the German-speaking part probably have less severe dependence and therefore trigger less use of formal and informal care. Regional differences in Switzerland can be linked both to cultural aspects and to policy-related incentives from different cantons (see, e.g., Fuino and Wagner 2018, 2019).

Finally, let us briefly discuss the socio-related variables. The presence of children outside the household does not play a relevant role. We find that a higher number of persons in the household reduces formal care usage. The increase of the number of persons in the household by one standard deviation triggers a significant 0.298 decrease of standard deviation of formal care. At the same time, we observe a significant 0.108 increase in informal care. ${ }^{8}$ The opposite signs of these coefficients indicate a substitutional relationship between both types of care: the decrease in formal care is complemented with an increase of informal care delivered by household cohabitants. Overall, however, we observe a positive and significant correlation coefficient of 0.441 between the error terms $\epsilon_{F C R}$ and $\epsilon_{I C R}$. This result indicates that on a baseline both types of care are complementary.

To summarize this section, we can put the observations in relation with our initial conjectures laid out in Section 2. By showing the significant effects of pathologies, age and BMI on dependence as well as the significance of dependence on both formal and informal care, we provide the necessary evidence to support the first conjecture. Further, we partially validate the second hypothesis: the gender and the linguistic regions are proven to significantly affect the usage for LTC. Education and income are not directly significant in the models (5) and (6). Further, while the presence of children outside of the household does not have a significant effect, the number of persons in the household impacts the demand for both types of LTC. We find that cohabitants act as informal caregivers reducing the demand for formal care. This yields to partial validation of Conjecture 3. Finally, our findings support the hypothesis of a positive correlation between formal and informal LTC.

\section{Concluding Remarks}

In this paper, we investigate and analyze the factors associated with dependence and the usage of formal and informal LTC. We develop a statistical model in a framework of structural equation modeling and calibrate it using the data of 4026 observations from the Swiss Health Survey. We model the concept of dependence as a latent variable with three manifest indicators, namely limitations in ADL, limitations in IADL and functional limitations. We allow for a direct effect of age, BMI and selected diseases on dependence which, in turn, is affecting the receipt of LTC. In other words, the effect

8 We have tested an alternative specification of our model (Equations (5) and (6)) that includes the interaction term $S E X \cdot N P R$ between the gender and the number of persons in the household. Although including the interaction term does not improve the goodness-of-fit of the model (see also Footnote 6), it is worthwhile studying if the effect of the number of persons in the household (a proxy for being single or widowed respectively living in a couple) is the same for males and females in terms of need for care. When including the interaction term, several coefficients (SEX, NPR and SEX - NPR for informal care) are not significant. Nonetheless, we find that the coefficient of the interaction term is positive and significant for formal care usage. This means that female respondents with male spouses use more formal care. This asymmetric effect can be related to the fact that men are often worse care providers (compare, e.g., with the findings in Fuino et al. 2019). 
of such factors is mediated via dependence. In addition, we account for socio-demographic factor and factors related to the social environment as drivers of the demand and usage for LTC. Finally, we let formal and informal care correlate to investigate the nature of the relation.

Our main findings can be summarized as follows: (1) the indirect effects of age, BMI and pathologies on the receipt of LTC are significant while mediated via the latent dependence variable, (2) socio-demographic and social environment variables as the gender, the linguistic region and the number of persons in the household play a significant role in determining the LTC needs and (3) the relation of formal and informal care can be both substitutional and complementary depending on a context.

Our observations underline the importance to incorporate the path analysis instead of directly assuming a causal link between formal and informal care. We also add to the understanding of the relationship between formal and informal care. This paper reinforces the importance of medical characteristics of elderly people, when studying the evolution of needs of impaired elderly people. Finally, our results give indications and insights for the rapid development of new LTC insurance products. The purpose of this paper is to explain selected factors that affect LTC use, rather than to predict the demand for LTC. Therefore, the study is limited in potential applications to the process of insurance products' pricing, for example, due to the choice of methodology and the bias of the sample. However, our research can serve as a basis for an underwriting questionnaire to assess the risk presented by new customers.

Author Contributions: Conceptualization, J.W.; formal analysis, I.R.; writing-original draft preparation, I.R.; writing-review and editing, I.R. and J.W.; supervision, J.W.

Funding: Financial support from the Swiss National Science Foundation (grant no. 100018_169662) is gratefully acknowledged.

Acknowledgments: Data from the "Enquête suisse sur la santé 1992, 1997, 2002, 2007, 2012 et 2017" has been provided by the Swiss Federal Statistical Office to the authors (contract no. 180239, ref. 624.110-1).

Conflicts of Interest: The authors declare no conflict of interest.

\section{References}

Bakx, Pieter, Claudine De Meijer, Frederik Schut, and Eddy van Doorslaer. 2015. Going Formal or Informal, Who Cares? The Influence of Public Long-Term Care Insurance. Health Economics 24: 631-43. [CrossRef] [PubMed]

Balia, Silvia, and Rinaldo Brau. 2014. A Country for Old Men? Long-Term Home Care Utilization in Europe. Health Economics 23: 1185-212. [CrossRef] [PubMed]

Baranoff, Etti G., Savas Papadopoulos, and Thomas W. Sager. 2007. Capital and Risk Revisited: A Structural Equation Model Approach for Life Insurers. Journal of Risk and Insurance 74: 653-81. [CrossRef]

Barczyk, Daniel, and Matthias Kredler. 2018. The Role of Informal and Formal Care. Working Paper. Madrid: McGill University, Universidad Carlos III de Madrid.

Beran, Tanya N., and Claudio Violato. 2010. Structural Equation Modeling in Medical Research: A Primer. BMC Research Notes 3: 267. [CrossRef] [PubMed]

Bolin, Kristian, Bjorn Lindgren, and Petter Lundborg. 2008. Informal and Formal Care among Single-Living Elderly in Europe. Health Economics 17: 393-409. [CrossRef] [PubMed]

Bonsang, Eric. 2009. Does Informal Care from Children to Their Elderly Parents Substitute for Formal Care in Europe? Journal of Health Economics 28: 143-54. [CrossRef] [PubMed]

Braini, M., J. Tuomilehto, W.-D. Heiss, N. M. Bornstein, P. M. W. Bath, Y. Teuschl, E. Richard, A. Guekht, and T. Quinn. 2015. Post-Stroke Cognitive Decline: An Update and Perspectives for Clinical Research. European Journal of Neurology 22: 229-316. [CrossRef]

Chappell, Neena L. 1985. Social Support and the Receipt of Home Care Services. The Gerontologist 25: 47-54. [CrossRef]

Charles, Kerwin Kofi, and Purvi Sevak. 2005. Can Family Caregiving Substitute for Nursing Home Care? Journal of Health Economics 24: 1174-90. [CrossRef] 
Christianson, Jon B. 1988. The Evaluation of the National Long Term Care Demonstration. The Effect of Channeling on Informal Caregiving. Health Services Research 23: 99-117.

Coe, Norma B., and Courtney Harold Van Houtven. 2009. Caring for Mom and Neglecting Yourself? The Health Effects of Caring for an Elderly Parent. Health Economics 18: 991-1010. [CrossRef]

De Laet, C., J. A. Kanis, A. Odén, H. Johanson, O. Johnell, P. Delmas, J. A. Eisman, H. Kroger, S. Fujiwara, P. Garnero, and et al. 2005. Body Mass Index as a Predictor of Fracture Risk: A Meta-Analysis. Osteoporosis International 16: 1330-38. [CrossRef]

De Meijer, Claudine, Marc Koopmanschap, Teresa Bago D'Uva, and Eddy van Doorslaer. 2011. Determinants of Long-Term Care Spending: Age, Time to Death or Disability? Journal of Health Economics 30: 425-38. [CrossRef]

Denton, Margeret. 1997. The Linkages Between Informal and Formal Care of the Elderly. Canadian Journal on Aging/La Revue Canadienne du Vieillissement 16: 30-50. [CrossRef]

Eling, Martin, and Sebastian D. Marek. 2013. Corporate Governance and Risk Taking: Evidence From the U.K. and German Insurance Markets. Journal of Risk and Insurance 81: 653-82. [CrossRef]

Finlayson, Marcia. 2002. Changes Predicting Long-Term Care Use Among the Oldest-Old. The Gerontologist 42: 443-53. [CrossRef]

Freedman, Vicki A., and Linda G. Martin. 1999. The Role of Education in Explaining and Forecasting Trends in Functional Limitations among Older Americans. Demography 36: 461-73. [CrossRef]

Fried, Linda P., Catherine M. Tangen, Jeremy Walston, Anne B. Newman, Calvin Hirsch, John Gottdiener, Teresa Seeman, Russell Tracy, Willem J. Kop, Gregory Burke, and et al. 2001. Frailty in Older Adults: Evidence for a Phenotype. The Journals of Gerontology, Series A: Biological Sciences and Medical Sciences 56: M146-57. [CrossRef]

Fuino, Michel, Iegor Rudnytskyi, and Joël Wagner. 2019. On the Characteristics of Reporting ADL Limitations and Formal LTC Usage across Europe. Working Paper. Lausanne: University of Lausanne.

Fuino, Michel, and Joël Wagner. 2018. Old-Age Care Prevalence in Switzerland: Drivers and Future Development. European Actuarial Journal 8: 321-62. [CrossRef]

Fuino, Michel, and Joël Wagner. 2019. Duration of Long-Term Care: Socio-Economic Drivers, Evolution and Type of Care Interactions. Working Paper. Lausanne: University of Lausanne.

GBD DALYs, and HALE Collaborators. 2017. Global, regional, and national disability-adjusted life-years (DALYs) for 333 diseases and injuries and healthy life expectancy (HALE) for 195 countries and territories, 1990-2016: A systematic analysis for the Global Burden of Disease Study. Lancet 390: 1260-344.

Gentili, Elena, Giuliano Masiero, and Fabrizio Mazzonna. 2017. The Role of Culture in Long-Term Care Arrangement Decisions. Journal of Economic Behavior \& Organization 143: 186-200. [CrossRef]

Gregg, Edward W., Yiling J. Cheng, Betsy L. Cadwell, Giuseppina Imperatore, Desmond E. Williams, Katherine M. Flegal, K. M. Venkat Narayan, and David F. Williamson. 2005. Secular Trends in Cardiovascular Disease Risk Factors According to Body Mass Index in US Adults. The Journal of the American Medical Association 293: 1868-75. [CrossRef]

Hanaoka, Chie, and Edward C. Norton. 2008. Informal and Formal Care for Elderly Persons: How Adult Children's Characteristics Affect the Use of Formal Care in Japan. Social Science E Medicine 67: 1002-8. [CrossRef]

Headen, Alvin E., Jr. 1993. Economic Disability and Health Determinants of the Hazard of Nursing Home Entry. The Journal of Human Resources 28: 80-110. [CrossRef]

Hooper, Daire, Joseph Coughlan, and Michael Mullen. 2008. Structural Equation Modelling: Guidelines for Determining Model Fit. Electronic Journal on Business Research Methods 6: 53-60. [CrossRef]

House, James S., Ronald C. Kessler, and A. Regula Herzog. 1990. Age, Socioeconomic Status, and Health. The Milbank Quarterly 68: 383-411. [CrossRef]

Huisman, Martijn, Anton E. Kunst, and Johan P. Mackenbach. 2003. Socioeconomic Inequalities in Morbidity among the Elderly; A European Overview. Social Science \& Medicine 57: 861-73. [CrossRef]

Jette, Alan M., Sharon Tennstedt, and Sybil Crawford. 1995. How Does Formal and Informal Community Care Affect Nursing Home Use? The Journals of Gerontology, Series B: Psychological Sciences and Social Sciences 50: S4-S12. [CrossRef] 
Katz, Sidney, Amasa B. Ford, Roland W. Moskowitz, Beverly A. Jackson, and Marjorie W. Jaffe. 1963. Studies of Illness in the Aged. The Index of ADL: A Standardized Measure of Biologic and Psychologic Function. The Journal of the American Medical Association 185: 94-99. [CrossRef]

Kemper, Peter. 1992. The Use of Formal and Informal Home Care by the Disabled Elderly. Health Services Research 27: 421-51.

Kim, Hyuncheol Bryant, and Wilfredo Lim. 2015. Long-Term Care Insurance, Informal Care, and Medical Expenditures. Journal of Public Economics 125: 128-42. [CrossRef]

Kurth, T., J. M. Gaziano, K. Berger, C. S. Kase, K. M. Rexrode, N. R. Cook, J. E. Buring, and J. E. Manson. 2002. Body Mass Index and the Risk of Stroke in Men. Archives of Internal Medicine 162: 2557-62. [CrossRef]

Langa, Kenneth M., Michael E. Chernew, Mohammed U. Kabeto, A. Regula Herzog, Mary Beth Ofstedal, Robert J. Willis, Robert B. Wallace, Lisa M. Mucha, Walter L. Straus, and A. Mark Fendrick. 2001a. National Estimates of the Quantity and Cost of Informal Caregiving for the Elderly with Dementia. Journal of General Internal Medicine 16: 770-78. [CrossRef]

Langa, Kenneth M., Michael E. Chernew, Mohammed U. Kabeto, and Steven J. Katz. 2001b. The Explosion in Paid Home Health Care in the 1990s: Who Received the Additional Services? Medical Care 39: 147-57. [CrossRef]

Lo Sasso, Anthony T., and Richard W Johnson. 2002. Does Informal Care from Adult Children Reduce Nursing Home Admissions for the Elderly? INQUIRY: The Journal of Health Care Organization, Provision, and Financing 39: 279-97. [CrossRef]

Lu, Bin, Xin Yuan Song, and Xin Dan Li. 2012. Bayesian Analysis of Multi-Group Nonlinear Structural Equation Models with Application to Behavioral Finance. Quantitative Finance 12: 477-88. [CrossRef]

Lutz, Wolfgang, Warren Sanderson, and Sergei Scherbov. 2008. The Coming Acceleration of Global Population Ageing. Nature 451: 716-19. [CrossRef]

Michaud, Pierre-Carl, and Arthur van Soest. 2008. Health and Wealth of Elderly Couples: Causality Tests Using Dynamic Panel Data Models. Journal of Health Economics 27: 1312-25. [CrossRef]

Mommaerts, Corina. 2018. Are Coresidence and Nursing Homes Substitutes? Evidence from Medicaid Spend-Down Provisions. Journal of Health Economics 59: 125-38. [CrossRef]

Muthén, Bengt O. 1993. Goodness of Fit With Categorical and Other Nonnormal Variables. In Testing Structural Equation Models. Edited by K. A. Bollen and J. S. Long. Newbury Park: Sage Publications, chp. 9, pp. 205-34.

Nachtigall, Cristof, Ulf Kroehne, Friedrich Funke, and Rolf Steyer. 2003. (Why) Should We Use SEM? Pros and Cons of Structural Equation Modeling. Methods Psychological Research Online 8: 1-22.

Newman, Sandra J., Raymond Struyk, Paul Wright, and Michelle Rice. 1990. Overwhelming Odds: Caregiving and the Risk of Institutionalization. The Journals of Gerontology, Series B: Psychological Sciences and Social Sciences 45: S173-83. [CrossRef]

Pezzin, Liliana E., Peter Kemper, and James Reschovsky. 1996. Does Publicly Provided Home Care Substitute for Family Care? Experimental Evidence with Endogenous Living Arrangements. The Journal of Human Resources 31: 650-76. [CrossRef]

Pi-Sunyer, Xavier. 1991. Health Implications of Obesity. American Journal of Clinical Nutrition 53: 1595S-603S. [CrossRef]

Prince, Martin, Renata Bryce, Emiliano Albanese, Anders Wimo, Wagner Ribeiro, and Cleusa P. Ferri. 2013. The global prevalence of dementia: A systematic review and metaanalysis. Alzheimers Dement 9: 63-75. [CrossRef]

Rahmqvist, Mikael. 2001. Patient Satisfaction in Relation to Age, Health Status and Other Background Factors: A Model for Comparisons of Care Units. International Journal for Quality in Health Care 13: 385-90. [CrossRef]

Renehan, Andrew G, Margaret Tyson, Matthias Egger, Richard F. Heller, and Marcel Zwahlen. 2008. Body-Mass Index and Incidence of Cancer: A Systematic Review and Meta-Analysis of Prospective Observational Studies. Lancet 371: 569-78. [CrossRef]

Rexrode, K. M., C. H. Hennekens, W. C. Willett, G. A. Colditz, M. J. Stampfer, J. W. Rich-Edwards, F. E. Speizer, and J. E. Manson. 1997. A Prospective Study of Body Mass Index, Weight Change, and Risk of Stroke in Women. The Journal of the American Medical Association 277: 1539-45. [CrossRef]

Rodrigues, Ricardo, Stefania Ilinca, and Andrea E. Schmidt. 2018. Income-Rich and Wealth-Poor? The Impact of Measures of Socio-Economic Status in the Analysis of the Distribution of Long-Term Care Use among Older People. Health Economics 27: 637-46. [CrossRef] 
Rosseel, Yves. 2012. lavaan: An R Package for Structural Equation Modeling. Journal Of Statistical Software 48: 1-36. [CrossRef]

Scheil-Adlung, Xenia. 2015. Long-Term Care Protection for Older Persons: A Review of Coverage Deficits in 46 Countries. Working Paper. Geneva: International Labour Office.

Shapiro, Evelyn, and Robert B. Tate. 1985. Predictors of Long Term Care Facility Use Among the Elderly. Canadian Journal on Aging/La Revue Canadienne Du Vieillissement 4: 11-19. [CrossRef]

Spector, William D., Sidney Katz, John B. Murphy, and John P. Fulton. 1987. The Hierarchical Relationship Between Activities of Daily Living and Instrumental Activities of Daily Living. Journal of Chronic Diseases 40: 481-89. [CrossRef]

Swiss Federal Statistical Office. 2019. L'Enquête Suisse sur la Santé 2017 en Bref. Conception, Méthode, Réalisation. Neuchâtel: Swiss Federal Statistical Office.

Tomiak, Monica, Jean-Marie Berthelot, Eric Guimond, and Cameron A. Mustard. 2000. Factors Associated with Nursing-Home Entry for Elders in Manitoba, Canada. Journals of Gerontology-Series A Biological Sciences and Medical Sciences 55: M279-87. [CrossRef]

Torbica, Aleksandra, Stefano Calciolari, and Giovanni Fattore. 2015. Does Informal Care Impact Utilization of Healthcare Services? Evidence from a Longitudinal Study of Stroke Patients. Social Science E Medicine 124: 29-38. [CrossRef]

Van Houtven, Courtney Harold, and Edward C. Norton. 2004. Informal Care and Health Care Use of Older Adults. Journal of Health Economics 23: 1159-80. [CrossRef]

Wagner, Melanie, and Martina Brandt. 2018. Long-term Care Provision and the Well-Being of Spousal Caregivers: An Analysis of 138 European Regions. The Journals of Gerontology, Series B: Psychological Sciences and Social Sciences 73: e24-e34. [CrossRef]

Weaver, France M., and Bryce A. Weaver. 2014. Does Availability of Informal Care within the Household Impact Hospitalisation? Health Economics, Policy and Law 9: 71-93. [CrossRef]

Witt, Brandi J., Steven J. Jacobsen, Susan A. Weston, Jill M. Killian, Ryan A. Meverden, Thomas G. Allison, Guy S. Reeder, and Véronique L. Roger. 2004. Cardiac Rehabilitation After Myocardial Infarction in the Community. Journal of the American College of Cardiology 44: 988-96. [CrossRef]

Wong, Albert, Rianne Elderkamp-De Groot, Johan Polder, and Job Van Exel. 2010. Predictors of long-term care utilization by Dutch hospital patients aged 65+. BMC Health Services Research 10: 1-14. [CrossRef]

Wu, Shunquan, Rui Wang, Yanfang Zhao, Xiuqiang Ma, Meijing Wu, Xiaoyan Yan, and Jia He. 2013. The Relationship Between Self-Rated Health and Objective Health Status: A Population-Based Study. BMC Public Health 13: 320. [CrossRef]

(C) 2019 by the authors. Licensee MDPI, Basel, Switzerland. This article is an open access article distributed under the terms and conditions of the Creative Commons Attribution (CC BY) license (http://creativecommons.org/licenses/by/4.0/). 